ISSN 1112-9867

\title{
A VARIABLE SAMPLING INTERVAL EWMA T CONTROL CHART WITH UNKNOWN SHIFT SIZE
}

\author{
P. S. $\mathrm{Ng}^{1, *}$, M. B. C. Khoo ${ }^{1}$, W. C. Yeong ${ }^{2}$ and S. L. Lim $^{3}$ \\ ${ }^{1}$ School of Mathematical Sciences, UniversitiSains Malaysia, 11800 Penang, Malaysia \\ ${ }^{2}$ Department of Operations and Management Information Systems, Faculty of Business and \\ Accountancy,Universiti Malaya, 50603 Kuala Lumpur, Malaysia \\ ${ }^{3}$ Institute of Mathematical Sciences, Faculty of Science, Universiti Malaya, 50603 Kuala \\ Lumpur, Malaysia
}

Published online: 17 October 2017

\begin{abstract}
The process standard deviation of Exponentially Weighted Moving Average t(EWMA t) type charts does not need to be estimated in setting up the control limits for tracking mean differences and thus the estimation errors in the process standard deviation can be avoided. However, most of the proposed control charts in the literature assumed the shift size to be known, whereby in reality the exact shift size could not be determined by quality practitioners. Therefore, this paper proposed the used of the expected average time to signal (EATS) to measure the performance of variable sampling interval EWMA t (VSI EWMA t) chart when the shift size could not be specified. The EATS of the proposed chart is numerically demonstrated and the results are compared with its competing charts. In the detection of the shift, VSI EWMA t chart outperforms the $\mathrm{t}$ chart, the VSI $\mathrm{t}$ chart and the EWMA $\mathrm{t}$ chart.
\end{abstract}

Keywords: variable sampling interval exponentially weighted moving average t chart; shift size; expected average time to signal.

Author Correspondence, e-mail: sang_ng@hotmail.com

doi: http://dx.doi.org/10.4314/jfas.v9i5s.38 


\section{INTRODUCTION}

Statistical process control (SPC) is widely used to monitor, improve and achieve process stability in manufacturing industries. Control chart is one of the powerful and promising methods in SPC and it was first proposed by Walter A. Shewhart in the 1920's [1]. Since the Shewhart's pioneering work, the control chart framework has been evolving continuously and the application of control charts has greatly increased through a wide variety of research publications. For instance, control chart has been successfully applied in applications across diverse areas, such as ceramic substrate production line [2], healthcare [3-4], financial service [5] and manufacturing industries [6-7].

Among different types of chart, control charts like $\bar{X}$ and Exponentially Weighted Moving Average (EWMA) $\bar{X}$ charts are commonly employed in manufacturing industries. However, the main shortcoming of $\overline{\mathrm{X}}$ chart is the nominal process standard deviation $\sigma_{0}$ in setting up control limits need to be estimated. The error in estimation of $\sigma_{0}$ will cause different false alarm rates and thus the detection of chart on the changes of the process mean chart becomes insensitive. To circumvent this problem,in [8] developed EWMA t chart based on the control static having $\mathrm{t}$ distribution. The property of $\mathrm{t}$ chart does not require any samples from phase 1 in estimating $\sigma_{0}$, thereby the estimation error in process standard deviation can be avoided and thus the risk for the occurrence of false alarm can be minimized.

To avoid the several drawbacks of using average run length metric in EWMA t chart such as excessive variations of the run length, unsatisfactory run-length distribution and not suitable to evaluate complex detection schemes, in [9] proposed EWMA $t$ chart based on the performance measure of median run length. In [10] developed the synthetic $t$ chart and synthetic EWMA t chart. The results showed that synthetic $t$ chart always surpasses the $t$ chart for larger sample sizes, whereas synthetic EWMA t chart is shown to have better performance than EWMA tchart for larger shifts.

To meet the challenges of the $21^{\text {st }}$ century, adaptive chart which is more efficient in detecting the process changes is widely proposed to improve the slow response of conventional control charts. The main advantage of the adaptive chart is that it can be used to vary more than one chart's parameters such as sampling interval and sample size. Monitoring the adaptive control chart was kick started by [11] by introducing the variable sampling interval (VSI) properties. 
In [12-13] were then inspired by the VSI idea and developed variable sample size (VSS) $\overline{\mathrm{X}}$ chart. The VSS and VSI properties were then widely integrated into different types of control chart. More recent works on VSI-type charts and VSS-type charts were proposed by [14-17]. Concerning the adaptive EWMA t chart, in [18] has proposed variable sampling interval EWMA t (VSI EWMA t) chart to monitor the process mean recently. The results showed that the ATS performance of the VSI EWMA t chart were better than fixed sampling EWMA t chart. However, the warning limit parameter (e.g.W) in their proposed VSI EWMA t chart is not optimized.

A fundamental assumption made for most of the control chart construction in the existing literature is the shift size is known a priori. In practice, the quality practitioners may not be able to determine the actual shift size in situations where the shift size is unknown due to the lack of historical data and the shift size is varies and not deterministic due to some unknown stochastic models. As indicated by [19], inaccurate specification of the shift size will seriously affect the run length properties. For instance, the company will have to bear the cost of the early false alarms or large quantity of unwanted products being produced when the shift size is estimated wrongly. Thus, it is important to address the problem of random shift size in order to obtain the accurate detection of out of control. To the best of our knowledge, the adaptive EWMA t chart for unknown shift has not been proposed in the literature. To fill in the research gap, we consider the optimization algorithms for the optimality of two sampling intervals in the proposed VSI EWMA t chart with unknown shift size.

The remainder of the paper is structured as follows:An overview of the methodology of the VSI EWMA t chart is provided in Section 2. Following that, Section 3 presents the proposed VSI EWMA tchart with unknown shift size. The observations drawn from the proposed chart are summarized and discussed in Section 4. Lastly, conclusions are drawn in Section 5.

\section{THE VSI EWMA t CHART}

Assume the quality characteristic $X$ follows a normal $\mathrm{N}\left(\mathrm{u}_{0}+\mathrm{a} \sigma_{0}, \mathrm{~b} \sigma_{0}\right)$ distribution where $\mathrm{u}_{0}$ is the nominal process mean, $\sigma_{0}$ is the standard deviation, a represents the size of the mean shift and $b$ denotes the magnitude of a change (or error) in the process standard deviation. The process is statistically in control if $a=0$ and $b=1$. Otherwise, the process 
has shifted if $a \neq 0\left(\mathrm{u}_{0}\right.$ has changed $)$ or $\mathrm{b} \neq 1 \quad\left(\sigma_{0}\right.$ has changed $)$ or both $\mathrm{u}_{0}$ and $\sigma_{0}$ have changed.

Suppose we observe subgroups of $n$ observations, $\left\{X_{i, 1}, X_{i, 2}, \ldots, X_{i, n}\right\}$, at time $i=1,2, \ldots, i \in$ $\mathrm{N}$ (natural number). Assume $\mathrm{X}_{\mathrm{i}, \mathrm{j}} \sim \mathrm{N}\left(\mathrm{u}_{0}+\mathrm{a} \sigma_{0}, \mathrm{~b} \sigma_{0}\right), \mathrm{i}=1,2, \ldots, 1 \leq \mathrm{j} \leq \mathrm{n}$, and there is independence within and between subgroups. The subgroups mean $\bar{X}_{1}$ and standard deviation $S_{\mathrm{i}}$ can be calculated by:

$\bar{X}_{i}=\frac{1}{n} \sum_{j=1}^{n} X_{i, j}, \quad S_{i}=\sqrt{\frac{1}{n-1} \sum_{j=1}^{n}\left(X_{i, j}-\bar{X}_{1}\right)^{2}}(1)$

As proposed by [8], the control statistics $Y_{i}$ for the EWMA t chart is:

$$
\begin{gathered}
Y_{0}=0 \\
Y_{i}=\lambda T_{i}+(1-\lambda) Y_{i-1} \text { for } i=1,2, \ldots(2)
\end{gathered}
$$

where $\lambda \in(0,1]$ is the smoothing constant and $T_{i}$ is computed as:

$$
\mathrm{T}_{\mathrm{i}}=\frac{\overline{\mathrm{X}_{1}}-\mathrm{u}_{0}}{\mathrm{~S}_{\mathrm{i}} / \sqrt{\mathrm{n}}}, \mathrm{i}=1,2, \ldots
$$

Whereas, the UCL $\mathrm{U}_{\mathrm{t}}$ and $\mathrm{UCL}_{\mathrm{t}}$ of VSI EWMA t chart are the function of the smoothing constant (lambda), the in control average run length (ARL) and subgroup sizen.

To compute the ATS values, the Markov chain approach is used in this paper. Suppose that a discrete-time Markov chain with $p+2$ states is considered in this paperwhere states $1, \ldots, p$ are transient and state $\mathrm{p}+1$ is an absorbing state. The Markov chain's transition) probability matrix $\mathrm{P}$ is provided as:

$$
\mathrm{P}=\left(\begin{array}{cc}
\mathrm{Q}_{\mathrm{t}} & \mathrm{r} \\
0^{\mathrm{T}} & 1
\end{array}\right)=\left(\begin{array}{ccccc}
\mathrm{Q}_{1,1} & \mathrm{Q}_{1,2} & \cdots & \mathrm{Q}_{1, \mathrm{p}} & \mathrm{r}_{1} \\
\mathrm{Q}_{2,1} & \mathrm{Q}_{2,2} & \cdots & \mathrm{Q}_{2, \mathrm{P}} & \mathrm{r}_{2} \\
\vdots & \vdots & \ddots & \vdots & \vdots \\
\mathrm{Q}_{\mathrm{P}, 1} & \mathrm{Q}_{\mathrm{P}, 2} & \cdots & \mathrm{Q}_{\mathrm{P}, \mathrm{P}} & \mathrm{r}_{\mathrm{P}} \\
0 & 0 & \cdots & 0 & 1
\end{array}\right)(4)
$$

where $Q_{t}$ is the $p \times p$ matrix of transient probabilities, $0^{T}=(0,0, \ldots, 0)$ and the $p \times 1$ vector $r$ that satisfies $r=1-Q_{t} 1$ where 1 is a $p \times 1$ column vector of ones. The number of steps L until the process reaches the absorbing stage is a Discrete PHase-type (DPH) random variable associated with parameters $\left(Q_{t}, d\right)($ see $[20-21])$ where we let $d=$ $\left(d_{0}, d_{1}, \ldots, d_{p}\right)^{T}$ be the $(p \times 1)$ vector of initial probabilities that is associated with the $p$ transient states. This vector only contains a single element that is equal to 1 , the rest of the remaining entries are equal to zero. 
To obtain the transient probabilities $Q_{i, j}$ from the transition probability matrix $P$, the interval between LCL and UCL is devided into $\mathrm{p}=2 \mathrm{~m}+1$ subintervals of width $2 \delta$. Thus, $2 \delta=$ (UCL - LCL)/2p.Let $H_{j}, j=-m, \ldots,-1,0,1, \ldots m$, represent the midpoint of the jth subinterval, the probabilities of $Q_{i, j}$ and the $d_{j}$ for the initial probabilities vector $d$ are computed as follow:

$Q_{i, j}=F_{t}\left(\frac{H_{j}+\delta-(1-\lambda) H_{i}}{\lambda} \mid n-1, \frac{a \sqrt{n}}{b}\right)-F_{t}\left(\frac{H_{j}-\delta-(1-\lambda) H_{i}}{\lambda} \mid n-1, \frac{a \sqrt{n}}{b}\right)(5)$

where $_{\mathrm{t}}(. . \mid \mathrm{e}, \mathrm{f})$ refers to the cumulative distribution function of a non-central $\mathrm{t}$ distribution with e degrees of freedom and non-centrality parameter $\mathrm{f}$.

$\mathrm{d}_{\mathrm{j}}=\left\{\begin{array}{rr}1 & \text { if } \mathrm{H}_{\mathrm{j}}-\delta<\mathrm{Y}_{0}<\mathrm{H}_{\mathrm{j}}+\delta \\ 0 & \text { otherwise }\end{array}(6)\right.$

By adopting the Equations (4)-(6), the ATS and ASI are derived and shown in the following expression [22]:

$$
\begin{gathered}
\text { ATS }=d^{T} Q g-d^{T} g \\
=d^{T}(Q-I) g(7)
\end{gathered}
$$

where $Q=\left(I-Q_{t}\right)^{-1}$ is the $p \times p$ fundamental matrix, $Q_{t}$ is the $p \times p$ matrix of transient probabilities, I is the identity matrix, $g$ is the $p \times 1$ vector of sampling intervals $\left(h_{S}, h_{L}\right)$ corresponding to the discretized states of the Markov chain and the initial probabilities vector $d$ is set as $d=(1,0, \ldots, 0)$ [22].

$$
\begin{aligned}
& \mathrm{ASI}=\mathrm{p}_{\mathrm{s}} \mathrm{h}_{\mathrm{s}}+\mathrm{p}_{\mathrm{L}} \mathrm{h}_{\mathrm{L}} \\
& =1++\frac{d^{T} g-1}{A R L_{0}}(8)
\end{aligned}
$$

where $p_{L}$ is the probability the sample adopts the long sampling interval while $p_{S}$ is the probability the sample adopts the short sampling interval.

\section{THE VSI EWMA t CHART WITH UNKNOWN SHIFT SIZE}

In the situation where the exact shift size $(\delta)$ is known, ATS is used as the performance measure in monitoring the statistical performance. On the other hand, if the shift size cannot be specified or the $\delta$ is not deterministic, the expected average time to signal,EATS $S_{1}$ acts as an alternative type of performance measure in measuring the statistical performance $[6,19,23]$. In this paper, $E A T S_{1}$ is considered as the expected value of the ATS over the distribution 
function $f_{\delta}(\delta)$ for the mean shift and it can be computed as follows:

$$
E A T S_{1}=\int f_{\delta}(\delta) \operatorname{ATS}\left(n, h_{S}, h_{L}, W, K, a, b\right) d \delta,
$$

where $f_{\delta}(\delta)$ denotes the probability distribution function of the shift $\delta$. In general, $\delta$ is assumed to follow a uniform distribution over the interval $\left(\delta_{\min }, \delta_{\max }\right)$ as it is often difficult to fit the actual shape of $f_{\delta}(\delta)$, where $\delta_{\min }$ and $\delta_{\max }$ represent the lower and upper bounds of the mean shift, respectively $[6,19,23]$. Note that the integral as shown in Equation (9) cannot be obtained easily, thus an approximation of the integral is computed by using Gauss-Legendre quadrature. In this paper, we consider the various combinations of $\left(\delta_{\text {min }}, \delta_{\text {max }}\right)$ such as $\left(\delta_{\min }, \delta_{\max }\right)=\{(0.25,2),(0.25,3),(0.5,2),(0.5,3),(0.75,2),(0.75,3)\}$ which are the shift size domains adopted in the studies of [24-25]. For the optimization criterion, the objective function of $E A T S_{1}$ is minimized and mathematically expressed as:

$$
\operatorname{Min}_{\left(n, h_{S}, h_{L}, W, K, a\right)} \operatorname{EATS}_{1}\left(\delta_{\text {min }}, \delta_{\text {max }}\right) \text { for } \delta_{\text {min }}<\delta_{\max }(10)
$$

subject to constraints

$$
\mathrm{ATS}_{0}=370.4(11)
$$

and

$$
p_{S} h_{s}+p_{L} h_{L}=1+\frac{d^{T} g-1}{A R L_{0}}(12)
$$

\section{NUMERICAL ANALYSIS}

To illustrate the proposed VSI EWMA t chart with the performance measure ofEATS, suppose we consider $n \in\{3,5,7\},\left(h_{S}, h_{L}\right) \in\{(0.5,1.5),(0.3,1.7),(0.1,1.3),(0.1,1.5),(0.1,1.9)$, $(0.1,4)\}$ and various combinations of $\left(\delta_{\min }, \delta_{\max }\right)$ as shown in Table 1.

\begin{tabular}{|c|c|c|c|c|c|c|c|c|c|}
\hline$n$ & $\delta_{m i}$ & $\delta_{m a}$ & $\left(\mathbf{h}_{\mathrm{S}}, \mathbf{h}_{\mathrm{L}}\right)$ & $(0.5,1.5)$ & $(0.3,1.7)$ & $(0.1,1.3)$ & $(0.1,1.5)$ & $(0.1,1.9)$ & $(0.1,4.0)$ \\
\hline 3 & 0. & 2 & $\left(W^{*}, K^{*}\right.$ & $(0.184$ & (0.191, & $(0.227$ & $(0.153$ & (0.351, & $(0.246$ \\
\hline & 2 & & $\lambda^{*}, E A T S$ & 0.757 & 0.746 & $0.800,0.03$ & 0.550 & 1.310, 0.07, & 0.971, \\
\hline
\end{tabular}

Table 1.VSI EWMA t chart's optimal chart parameters $\left(\mathrm{W}^{*}, K^{*}, \lambda^{*}\right)$ and the corresponding EATS $_{1}$ values when $A T S_{0}=370.4, A S I_{0}=1, n \in\{3,5,7\}$ and various combinations of

$$
\left(\delta_{\min }, \delta_{\max }\right)
$$




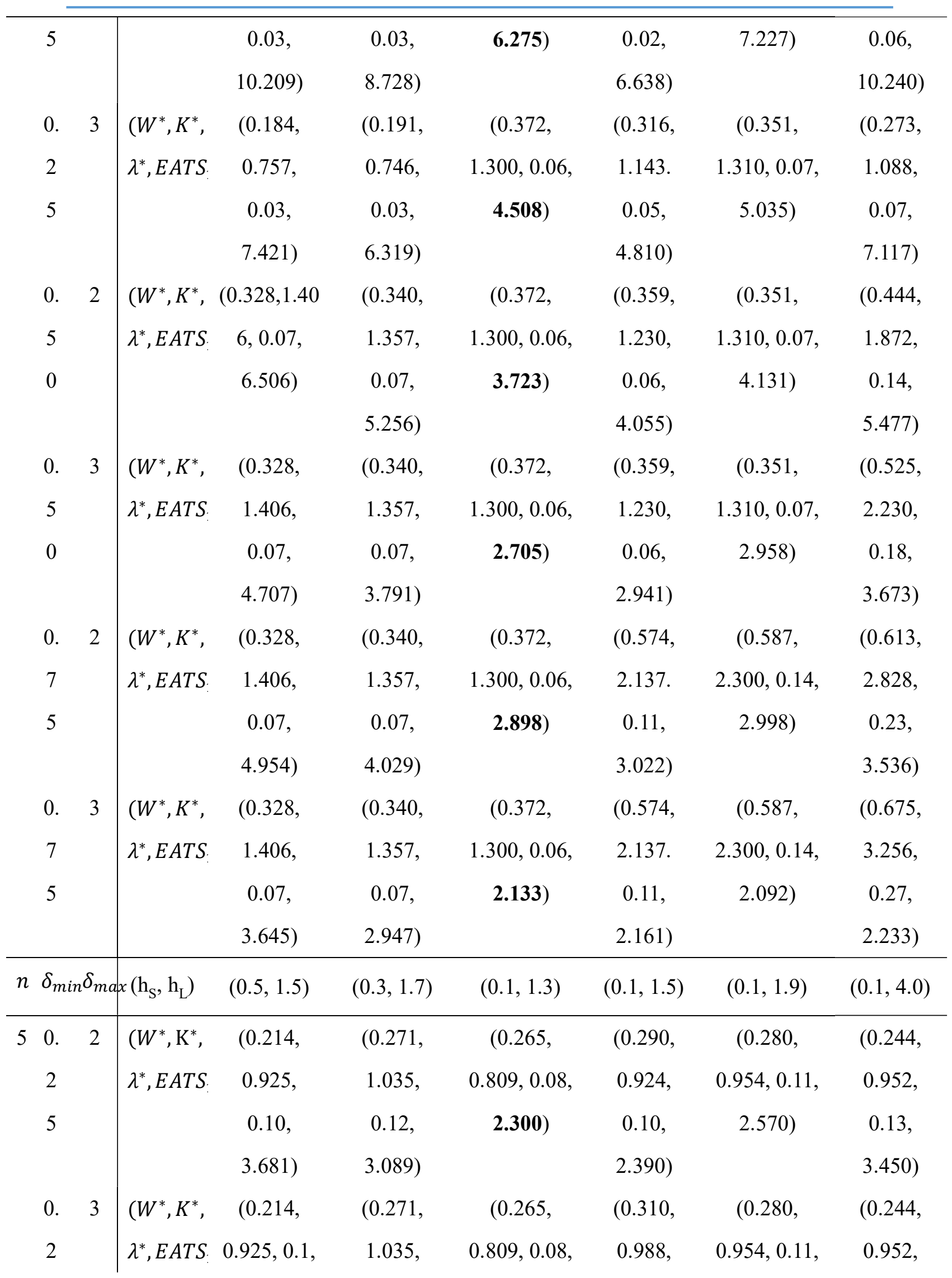




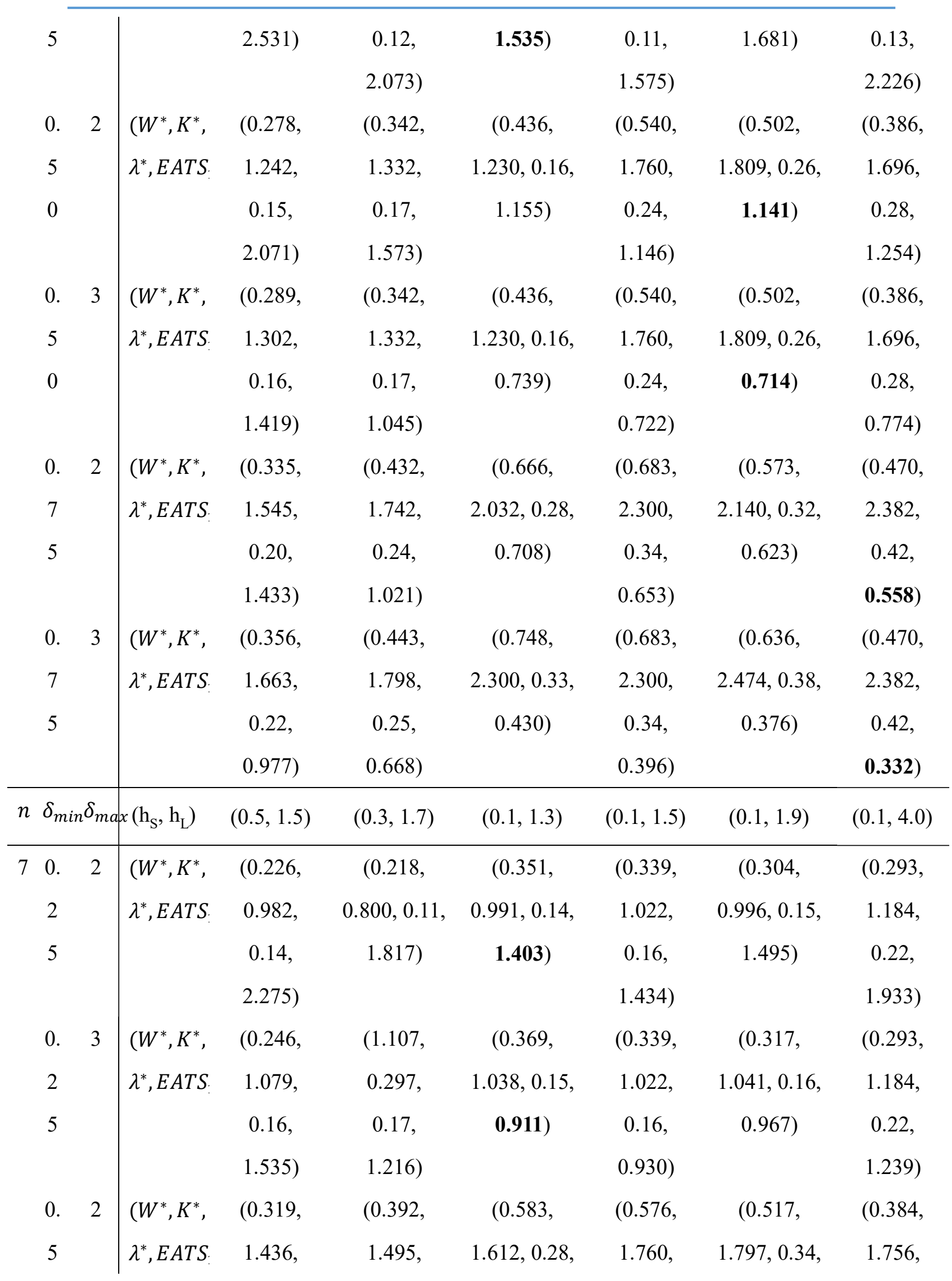




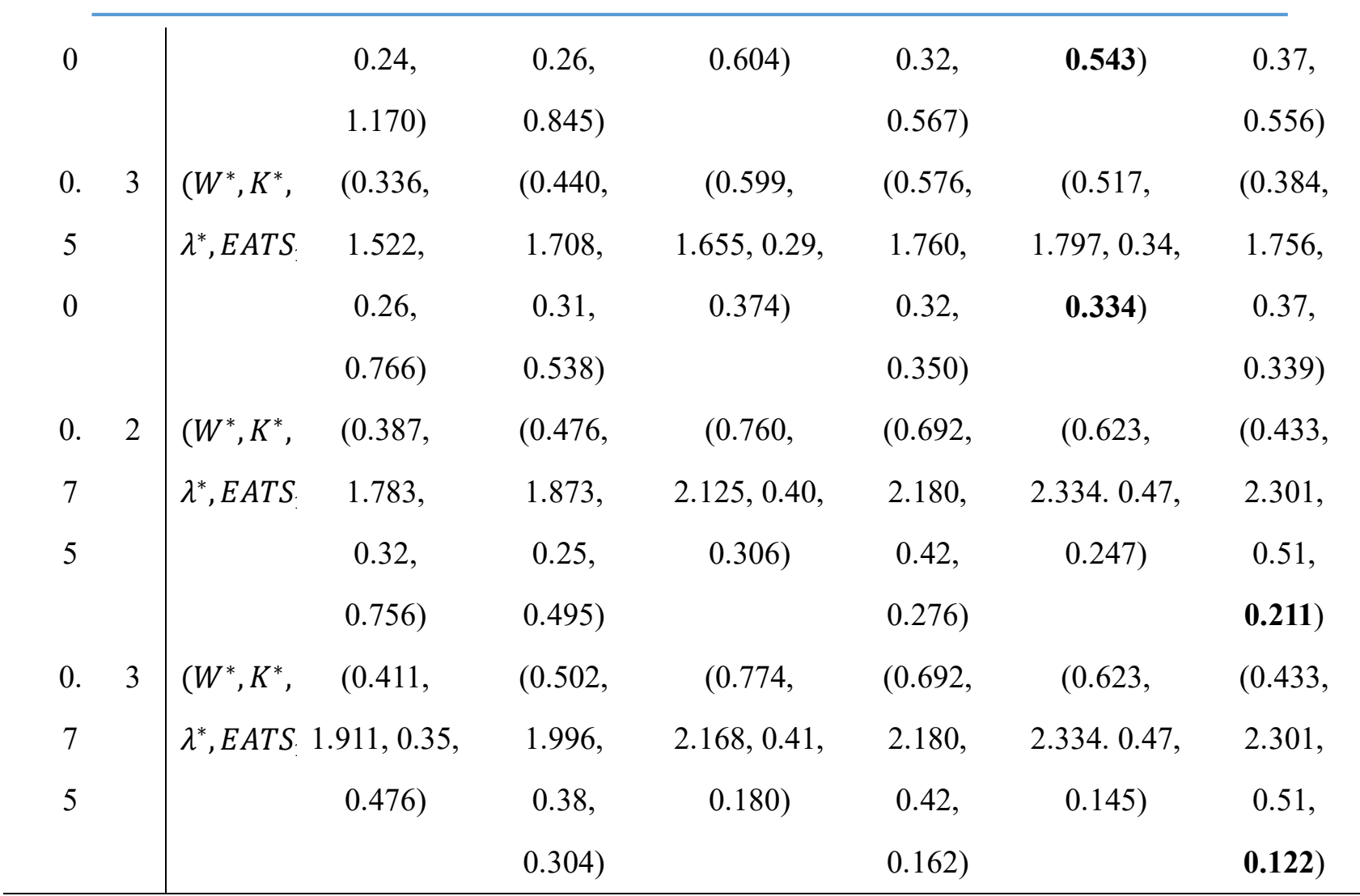

First, we compute the optimal charting parameters $\left(\lambda^{*}, W^{*}, K^{*}\right)$ that minimizes the EATS by using the methodology presented in Section 3. Then, we provide the overall effectiveness of the chart within a mean shift domain by computing the EATS 1 values based on the corresponding optimal parameters $\left(\lambda^{*}, W^{*}, K^{*}\right)$ obtained from the Scilab optimization program. Subsequently, the comparisons are made between the VSI EWMA t chart with three others charts such as the $t$ chart, the VSI $t$ chart and the EWMA $t$ chart with unknown shift size.

Table 1 presents the optimal parameters of $\left(\lambda^{*}, W^{*}, K^{*}\right)$ and their corresponding $E A T S_{1}$ values of the VSI EWMA t chart for various combinations of $\left(n, \delta_{\min }, \delta_{\max }\right)$. Based on Table 1 , the combination of $\left(h_{S}, h_{L}\right)=(0.1,1.3)$ results in the lowest $E A T S_{1}$ values (refer to the values in bold) for $n=3$, whereas the VSI EWMA $t$ chart tends to generate a lower $E A T S_{1}$ for higher shift domain for the combinations of $\left(h_{S}, h_{L}\right)=(0.1,1.9)$ and $\left(h_{S}, h_{L}\right)=$ $(0.1,4)$ (see values in bold). In addition, we also observe that the spread between $h_{S}$ and $h_{L}$ significantly impact the value of EATS and the larger spread between $h_{S}$ and $h_{L}$ does not necessarily result in smaller $E A T S_{1}$ as different combinations of $\left(h_{S}, h_{L}\right)$ result in different optimal $K$ and $W$ values. These observations are supported by the studies of $[18,26]$. The 
choiceof the sample size $n$ also has a large impact on the $E A T S_{1}$. As expected, a larger $E A T S_{1}$ is obtained for smaller values of $n$, e.g. in Table 1 the $E A T S_{1}=10.209$ for $\left(n, h_{S}, h_{L}, \delta_{\min }, \delta_{\max }\right)=(3,0.5,1.5,0.25,2) \quad$ is larger than $E_{A T S_{1}}=3.681$ for $\left(n, h_{S}, h_{L}, \delta_{\min }, \delta_{\max }\right)=(5,0.5,1.5,0.25,2)$ and $E A T S_{1}=2.275$ for $\left(n, h_{S}, h_{L}, \delta_{\min }, \delta_{\max }\right)$ $=(7,0.5,1.5,0.25,2)$ respectively. Thus, a larger sample size is recommended to monitor the process mean.

Additionally, it is apparent from Table 1 that the $\mathrm{EATS}_{1}$ value for shift domain is impacted by the values of $\delta_{\min }$ and the range of the shift $\left(\delta_{\min }, \delta_{\max }\right)$. The higher the $\delta_{\min }$, the smaller is the EATS $_{1}$ values regardless of the values of $\delta_{\max }$. For example, by considering the case of $=5$ and $\left(h_{S}, h_{L}\right)=(0.5,1.5)$, the $E A T S_{1}$ value is 3.681 for $\left(\delta_{\min }, \delta_{\max }\right)=$ $(0.25,2)$, while for the higher $\delta_{\min }$ such as $\left(\delta_{\min }, \delta_{\max }\right)=(0.5,2)$ and $\left(\delta_{\min }, \delta_{\max }\right)=$ $(0.75,2)$, the $E A T S_{1}$ are only 2.071 and 1.433 respectively. For different range of the shifts $\left(\delta_{\min }, \delta_{\max }\right)$ but with the same $\delta_{\min }$, we observed that larger range of shift generates smaller $E A T S_{1}$ value. For instance, by considering $n=5,\left(h_{S}, h_{L}\right)=(0.5,1.5)$, the $E A T S_{1}$ for $\left(\delta_{\min }, \delta_{\max }\right)=(0.25,2)$ is 3.681 which is larger than $E A T S_{1}=2.531$ for $\left(\delta_{\min }, \delta_{\max }\right)=(0.25,3)$. Thus, it is apparent that the selection of $\left(\delta_{\min }, \delta_{\max }\right)$ plays an important role in impacting the EATS $_{1}$ values.

To evaluate the robustness of VSI EWMA $t$ chart against errors in estimating the changes in the process standard deviation, $\sigma_{0}$, we calculate the EATS $_{1}$ for different values of $\mathrm{b}$ such as $b \in\{0.9,0.95,1,1.05,1.1\}$. Note that $b \neq 1$ indicates that the process has shifted due to the change in standard deviation, $\sigma_{0}$. In this section, we consider $\left(h_{S}, h_{L}\right)=(0.1,1.3)$ for the VSI $t$ and VSI EWMA $t$ charts. The shift domain is set as $\left(\delta_{\min }, \delta_{\max }\right)=(0.25,2)$, the $A R L_{0}=A T S_{0}=370.4$ are attained for $\mathrm{t}$, VSI $\mathrm{t}$, EWMA t and VSI EWMA $\mathrm{t}$ charts so that a fair comparison can be made. 
Table 2. EATS $_{1}$ values for $t$, VSI $t$, EWMA t and VSI EWMA t charts when $n \in\{3,5,7\}$ and

\begin{tabular}{|c|c|c|c|c|c|c|c|c|}
\hline \multirow[b]{2}{*}{$n$} & \multirow[b]{2}{*}{$b$} & \multirow[b]{2}{*}{$E A T S_{1}$} & $t$ & \multicolumn{2}{|c|}{ VSI t } & \multicolumn{2}{|c|}{ EWMA t } & \multirow{2}{*}{$\begin{array}{c}\text { VSI } \\
\text { EWMA t } \\
E A T S_{1}\end{array}$} \\
\hline & & & $\begin{array}{l}\% \\
\text { increase }\end{array}$ & $E A T S_{1}$ & $\begin{array}{l}\% \\
\text { increase }\end{array}$ & $E A T S_{1}$ & $\begin{array}{l}\% \\
\text { increase }\end{array}$ & \\
\hline \multirow[t]{5}{*}{3} & 0.9 & 95.90 & 1707.1 & 94.897 & 1688.1 & 13.52 & 154.7 & 5.31 \\
\hline & 0.95 & 102.04 & 1647.1 & 101.064 & 1630.3 & 14.39 & 146.4 & 5.84 \\
\hline & 1 & 108.08 & 1622.4 & 107.119 & 1607.2 & 15.25 & 143.0 & 6.28 \\
\hline & 1.05 & 113.99 & 1595.2 & 113.058 & 1581.3 & 16.12 & 139.7 & 6.72 \\
\hline & 1.1 & 119.79 & 1566.0 & 118.879 & 1553.3 & 17.00 & 136.5 & 7.19 \\
\hline$n$ & $b$ & $E{ }^{\prime} T S_{1}$ & $\begin{array}{l}\% \\
\text { increase }\end{array}$ & $\mathrm{E} A T S_{1}$ & $\begin{array}{l}\% \\
\text { increase }\end{array}$ & $E A T S_{1}$ & $\begin{array}{l}\% \\
\text { increase }\end{array}$ & $E A T S_{1}$ \\
\hline \multirow[t]{5}{*}{5} & 0.9 & 35.78 & 1785.7 & 22.00 & 1070.0 & 5.77 & 203.9 & 1.90 \\
\hline & 0.95 & 39.27 & 1769.5 & 24.96 & 1088.4 & 6.17 & 193.6 & 2.10 \\
\hline & 1 & 42.81 & 1761.1 & 27.72 & 1108.9 & 6.58 & 185.9 & 2.30 \\
\hline & 1.05 & 46.39 & 1748.9 & 30.72 & 1124.5 & 7.00 & 179.0 & 2.51 \\
\hline & 1.1 & 49.99 & 1733.4 & 33.69 & 1135.7 & 7.42 & 172.1 & 2.73 \\
\hline$n$ & $b$ & $E A T S_{1}$ & $\begin{array}{l}\% \\
\text { increase }\end{array}$ & $E A T S_{1}$ & $\begin{array}{l}\% \\
\text { increase }\end{array}$ & $E A T S_{1}$ & $\begin{array}{l}\% \\
\text { increase }\end{array}$ & $E A T S_{1}$ \\
\hline \multirow[t]{5}{*}{7} & 0.9 & 18.60 & 1574.9 & 14.34 & 1191.4 & 4.05 & 265.0 & 1.11 \\
\hline & 0.95 & 20.76 & 1557.6 & 16.29 & 1200.7 & 4.34 & 246.3 & 1.25 \\
\hline & 1 & 23.00 & 1540.0 & 18.33 & 1206.7 & 4.63 & 230.26 & 1.40 \\
\hline & 1.05 & 25.30 & 1523.3 & 20.43 & 1210.8 & 4.93 & 216.2 & 1.56 \\
\hline & 1.1 & 27.66 & 1510.0 & 22.60 & 1215.6 & 5.23 & 204.7 & 1.72 \\
\hline
\end{tabular}

As presented in Table 2, we can see slight changes in EATS $_{1}$ values across different values of $\mathrm{b}$ for VSI EWMA t chart. The VSI EWMA t chart also results in the best performance as it has the smallest EATS $_{1}$ value compared to $t$ chart, VSI $t$ chart and EWMA $t$ chart. For an example, when $\mathrm{n}=5$, and $\mathrm{b}=0.9$, the $\mathrm{EATS}_{1}$ value for VSI EWMA $\mathrm{t}$ chart, EWMA $\mathrm{t}$ chart, VSI $\mathrm{t}$ 
chart and t chart are 1.9, 5.77, 22 and 35.78 respectively. Furthermore, Table 2 also shows the percentage of increase in the EATS 1 values of the adopted competing charts. Note that the percentage of increase in the EATS $_{1}$ is reducing when bis larger. However, it is not surprising that different values of $b$ have minimal impact on the EATS $_{1}$ values of the different types of $\mathrm{t}$ charts as $\sigma_{0}$ does not need to be estimated in setting up the control limits of $t$ type charts and thus, the problem of getting an inappropriate estimate of $\sigma_{0}$ can be avoided [18].

\section{CONCLUSION}

This paper allows practitioners to select the suitable sample size $\mathrm{n}$, spread of $\left(\mathrm{h}_{\mathrm{S}}, \mathrm{h}_{\mathrm{L}}\right)$ and shift domain $\left(\delta_{\min }, \delta_{\max }\right)$ in determining the optimal chart parameters and their expected average time to signal EATS ${ }_{1}$ when the shift size is unknown and when the process standard deviation $\sigma_{0}$ has changed.

Comparisons show that the VSI EWMA $t$ chart outperforms the $t$ chart, VSI $t$ chart and EWMA t chart for different spread when the process is statistically in control and when the process has shifted due to the changes of $\sigma_{0}$.

\section{ACKNOWLEDGEMENTS}

The research is supported by the UniversitiSains Malaysia, Research University Grant number 1001/PMATHS/811263.

\section{REFERENCES}

[1] Montgomery D. C. Statistical quality control: A modern introduction. New York: John Wiley and Sons, 2009

[2] Luo H, Wu Z.Optimal np control charts with variable sample sizes or variable sampling intervals. Economic Quality Control, 2002, 17(1):39-61

[3] WoodallWH.The use of control charts in health-care and public-health surveillance. Journal of Quality Technology, 2006, 38(2):89-104

[4] Moscarelli M, Athanasiou T, SevdalisN, VescoviF, Fattouch K, Nasso G, Speziale G.Controlled exponentially weighted moving avarage chart in cardiac surgery: A simulation 
study across nine Italian cardiac centers. Seminars in Thoracic and Cardiovascular Surgery, 2016, 28(2):253-258

[5] Tsung F, Zhou ZH, Jiang W. Applying manufacturing batch techniques to fraud detection with incomplete customer information. IIE Transactions, 2007, 39:671-680

[6] Khaw KW, Khoo MBC, Yeong WC, Wu Z. Monitoring the coefficient of variation using a variable sample size and sampling interval control chart. Communications in Statistics-Simulation and Computation, 2016, 46(7):5772-5794

[7] Teoh WL, Khoo MBC, Castagliola P, Yeong WC, TehXY. The. Run-sum control charts for monitoring the coefficient of variation. European Journal of Operational Research, 2017, 257(1):144-158

[8] Zhang L, Chen G, Castagliola P. On $t$ and EWMA t charts for monitoring changes in the process mean. Quality and Reliability Engineering International, 2009, 25(8):933-945

[9] Chin WS, Khoo MBC.A study of the median run length (MRL) performance of the EWMA $t$ chart for the mean. South African Journal of Industrial Engineering, 2012, 23(3):42-55

[10]Calzada ME, Scariano SM.The synthetic t and synthetic EWMA t charts. Quality Technology and Quantitative Management, 2013, 10(1):37-56

[11]Reynolds MR, Amin RW, Nachlas JC. $\bar{X}$ charts with variable sampling intervals. Technometrics, 1988, 30(2):181-192

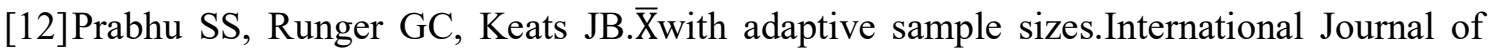
Production Research, 1993, 31(12):2895-2909

[13]CostaAFB. X charts with variable sample size. Journal of Quality Technology,1994, 26(3):155-163

[14]Chew XY, Khoo MBC, Teh SY, Lee MH.The run sum hotelling's $\chi^{2}$ control chart with variable sampling intervals. Quality and Reliability Engineering International, 2016, 32(7):2573-2590

[15]Ershadi M, Noorossana R, Niaki STA. Economic-statistical design of simple linear profiles with variable sampling interval. Journal of Applied Statistics, 2016, 43(8):1400-1418 [16]Zhou Q, Shu L, Jiang W. One-sided EWMA control charts for monitoring Poisson processes with varying sample sizes. Communications in Statistics-Theory and Methods, 2016, 45(20):6112-6132

[17]CostaAF, Machado MA.A side-sensitive synthetic chart combined with a VSS chart. Computers and Industrial Engineering, 2016, 91:205-214 
[18]Kazemzadeh RB, Karbasian M, Babakhani MA.An EWMA t chart with variable sampling intervals for monitoring the process mean. International Journal of Advanced Manufacturing Technology, 2013, 66(1-4):125-139

[19]Castagliola P, Celano G, Psarakis S. Monitoring the coefficient of variation using EWMA charts. Journal of Quality Technology, 2011, 43(3):249-265

[20]Neuts M.F.Matrix-geometric solutions in stochastic models: An algorithmic approach.New York: Dover Publications Inc., 1981

[21]Latouche G., Ramaswami V.Introduction to matrix analytic methods in stochastic modelling. Philadelphia: ASA SIAM, 1999

[22] Saccucci MS, Amin RW, Lucas JM. Exponentially weighted moving average control scheme with variable sampling intervals.Communications in Statistics-Simulationand Computation,1992, 21(3):627-657

[23]Wu Z, Ou Y, Castagliola P, Khoo MBC.A combined synthetic andX chart for monitoring the process mean.International Journal of Production Research, 2010, 48(24):7423-7436

[24]Khoo MBC, Teoh WL, Castagliola P, Lee MH. Optimal designs of the double sampling $\mathrm{X}$ chart with estimated parameters. International Journal of Production Economics, 2013, 144(1):345-357

[25]Lim SL, KhooMBC, Teoh WL, Xie M. Optimal designs of the variable sample size and sampling interval chart when process parameters are estimated. International Journal of Production Economics, 2015, 166:20-35

[26]Liu L, Chen B, Zhang J, Zi X. Adaptive phase II nonparametric EWMA control chart with variable sampling interval. Quality and Reliability EngineeringInternational,2015,31(1): 15-26

\section{How to cite this article:}

Ng P S, Khoo M B C, Yeong W C, Lim S L. A variable sampling interval ewma t control chart with unknown shift size. J. Fundam. Appl. Sci., 2017, 9(5S), 542-555. 